\title{
Multi-Nozzle Abrasive Water Jet for Oil and Gas Platforms Decommissioning: A Review
}

\author{
Wesam Salah Alaloul ${ }^{1}$, Muhammad Ali Musarat ${ }^{1,{ }^{*}}$, Lim Eu Shawn ${ }^{1}$, Ahmad Mahamad Al-Yacouby ${ }^{1}$, \\ Iraj Toloue ${ }^{1}$, Waqas Rafiq ${ }^{2}$, Waqas Farooq ${ }^{3}$ \\ ${ }^{1}$ Department of Civil and Environmental Engineering, Universiti Teknologi PETRONAS, Malaysia \\ ${ }^{2}$ Department of Civil Engineering, COMSATS University Islamabad Wah Campus, Pakistan \\ ${ }^{3}$ Department of Electrical Engineering, Sarhad University of Science \& Information Technology Peshawar, Pakistan
}

Received July 7, 2021; Revised August 23, 2021; Accepted September 21, 2021

\section{Cite This Paper in the following Citation Styles}

(a): [1] Wesam Salah Alaloul, Muhammad Ali Musarat, Lim Eu Shawn, Ahmad Mahamad Al-Yacouby, Iraj Toloue, Waqas Rafiq, Waqas Farooq, "Multi-Nozzle Abrasive Water Jet for Oil and Gas Platforms Decommissioning: A Review," Civil Engineering and Architecture, Vol. 9, No. 6, pp. 2062-2076, 2021. DOI: 10.13189/cea.2021.090634.

(b): Wesam Salah Alaloul, Muhammad Ali Musarat, Lim Eu Shawn, Ahmad Mahamad Al-Yacouby, Iraj Toloue, Waqas Rafiq, Waqas Farooq (2021). Multi-Nozzle Abrasive Water Jet for Oil and Gas Platforms Decommissioning: A Review. Civil Engineering and Architecture, 9(6), 2062-2076. DOI: 10.13189/cea.2021.090634.

Copyright $\mathrm{C} 2021$ by authors, all rights reserved. Authors agree that this article remains permanently open access under the terms of the Creative Commons Attribution License 4.0 International License

\begin{abstract}
Decommissioning offshore platforms present unique safety and health challenges to the oil and gas industry. In the Malaysian waters, there are over 300 fixed jacket platforms, and most of them exceeded the design service life of 25 to 30 years. One of the key challenges that determine the method of removal of aged jacket platforms is subsea cutting techniques. As underwater cutting is a challenging and expensive task, it is very much essential to develop cost-effective cutting techniques for decommissioning fixed jacket platforms. Thus, the objective of this paper is to present the state of art on Abrasive Water Jet (AWJ) cutting techniques by identifying the most significant parameters affecting the performance output measures for decommissioning of Jacket platforms applications. As the cutting process is very complex and times consuming tasks, the paper identifies research gaps and recommends new research areas in Multi Nozzles Abrasive Water Jet (MN-AWJ) for decommissioning applications. Many parameters are affecting the performance of AWJ that is why an in-depth critical review was adopted in this manuscript to determine the most significant parameters that need to be considered in the optimization of AWJ performance.
\end{abstract}

Keywords Abrasive Waterjet Technology, Erosion, Machining Processes, Material Cutting, MN-AWJ

\section{Introduction}

The power of water and its erosive effect has been serving the mankind for hundreds of years especially in the Roman Empire [1, 2]. The ancient Egyptians used sand combined with water for mining and cleaning. High-pressure water has been used for cutting in both forestry and mining. Abrasive waterjet is a manufacturing technique in which a high-pressure water stream mixed with hard particles removes material from a given object due to collision impact loads. This method is beneficial for processing hard or composite materials for engineering applications. The abrasive water jet system was applied for the first time in the United States. Modern industrial application of water jet technology was developed and get patented the concept of a high-pressure water jet cutting system in 1968 [3].

\subsection{Abrasive Water Jet}

Abrasive water jet (AWJ) is a processing method that has been used and widely adopted in the industry for cutting ductile materials such as aluminum, steel, alloys as well as brittle materials such as stone, concrete and ceramic $[4,5]$. The AWJ machining techniques are also used in a variety of applications namely for milling, polishing, drilling, and turning [6]. Abrasive jet machining is a nontraditional machine process that operates without 
producing shocks or heat $[4,7]$. In AWJ the cutting process takes place based on the erosion of the workpiece material caused by the impact of hard particles [6, 8]. A typical cross-sectional view of the AWJ nozzle [9] for common engineering applications is presented in Fig. 1.

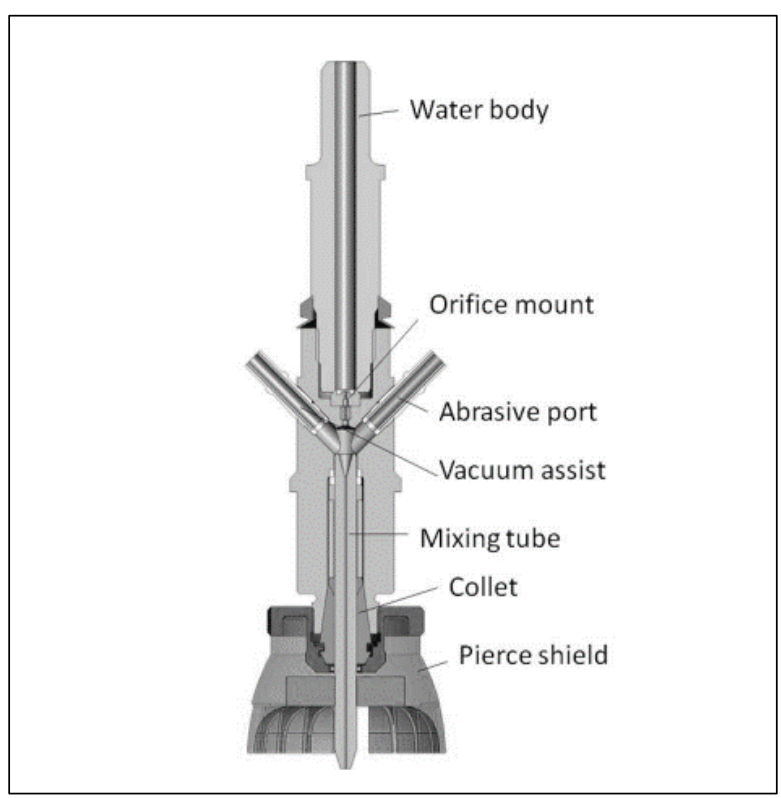

Figure 1. Typical details of AWJ nozzle components

\subsection{Components of Abrasive Water Jet}

As presented in Fig. 2, the AWJ system consists of a high-pressure water inlet, abrasive inlet, cutting head, water nozzle, mixing chamber, and focusing tube [9-11]. The important components of abrasive water jet are briefly discussed below:
- Water Pump: Pumps with pressure capacities up to $600 \mathrm{MPa}$ are normally used to generate high-pressure water in the tube above the orifice, where the fluid is forced to pass through a tinny opening.

- $\quad$ Abrasive materials: Abrasive are solid particles fed with high velocity into the mixing chamber through the abrasive port, where they coincide with the waterjet and are accelerated through the focusing tube. In some AWJ systems, excessive abrasive particles are normally flushed out by the flowing air to avoid clogging.

- Mixing head: The mixing head consists of the pressurized water supply line connected to the mixing chamber with an orifice, the abrasive supply line, the mixing chamber, and the focusing tube $[1,12]$.

- Workpiece: Is the target object metal being cut or shaped by the AWJ system. The workpiece is normally supported on a steel grid. Additional lateral supports are usually provided to restrict any displacement of the material which might influence the cutting accuracy.

- The collector: The collector is a container filled with water just below the workpiece. The main objective of the collector is to reduce the velocity of the water jet and keep the abrasive particles at the bottom of the tank. The top of the collector tank can be enclosed by covering sheets to prevent the dispersion of the volatile particles to the surrounding atmosphere.

- Moving Platform: The AWJ process the desired products by moving the jet nozzle across the workpiece to produce the required cut or finish. The motion of the nozzle is often performed by mounting on an $\mathrm{x}-\mathrm{y}$ table or three-dimensional shaping robots for more complex components.

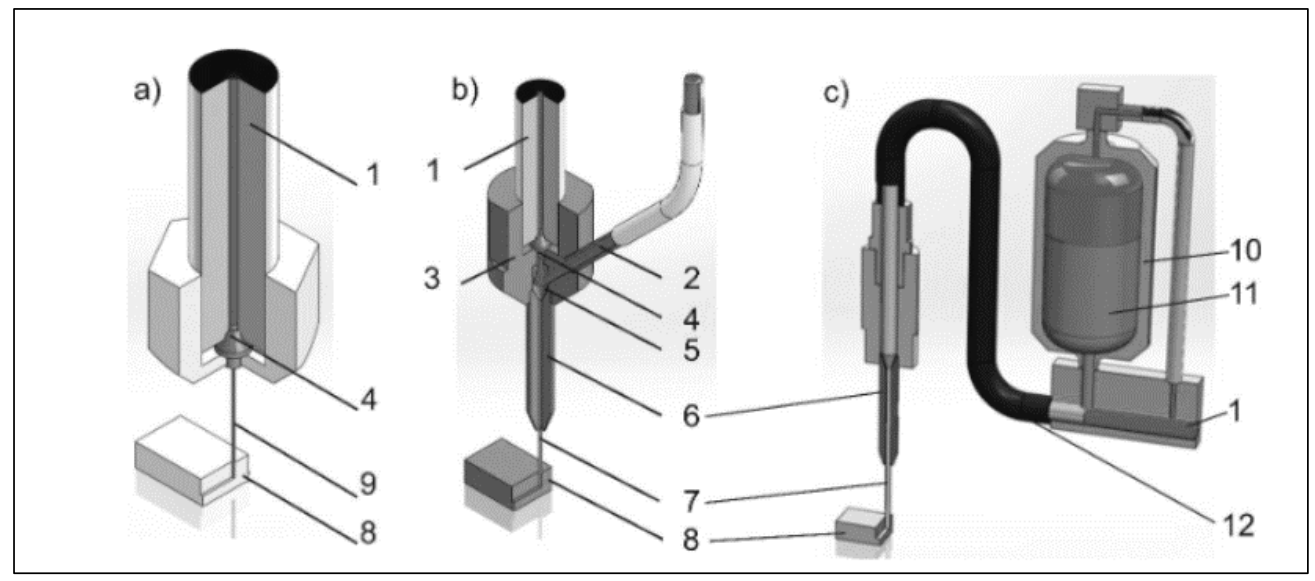

Figure 2. Schematic diagram: a) Water Jet cutting b) Abrasive Water Jet cutting, and c) Abrasive Suspension Water Jet: 1. High-pressure water inlet, 2. Abrasive inlet, 3. Cutting head, 4. Water nozzle, 5. Mixing chamber, 6. Focusing tube, 7. High-Speed Abrasive Water Jet, 8. Cutting sample, 9. High-Speed Water Jet, 10. Pressure vessel, 11. Wet abrasive, 12. High-pressure flexible hose 


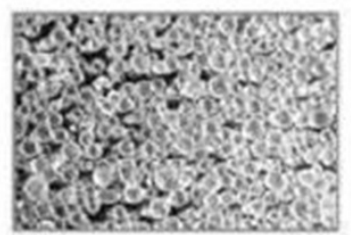

Glass Beads

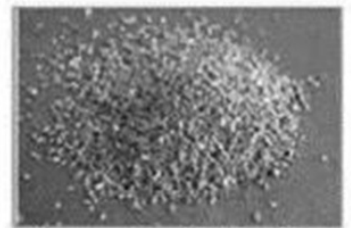

Brown Fused Alumina

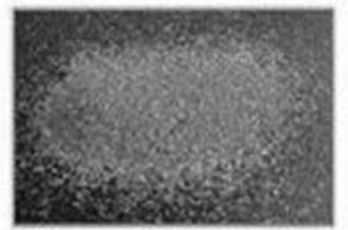

Green Silicon Carbide

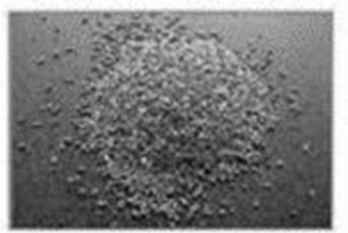

Stainless Steel Cut Wire

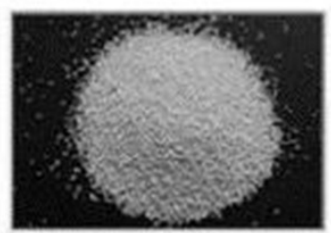

Ceramic Beads

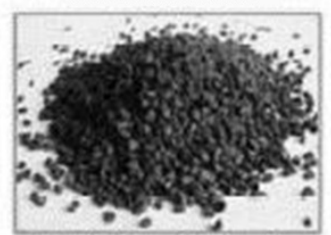

Black Fused Alumina

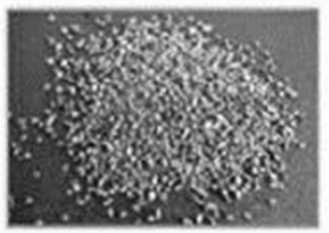

Steel Grit

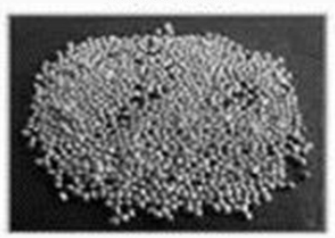

Zinc Cut Wire

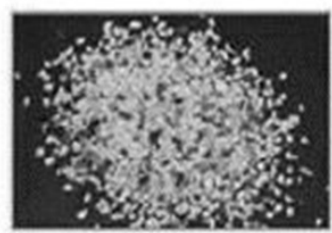

Plastic Blasting Media

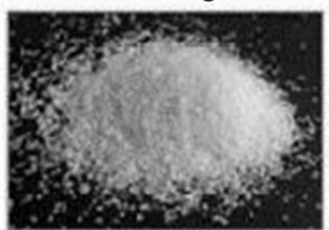

White Fused Alumina

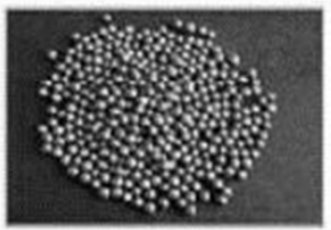

Steel Shot

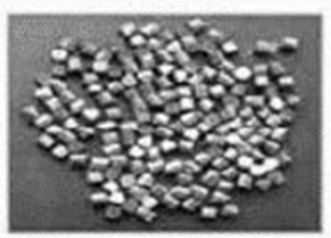

Copper Cut Wire

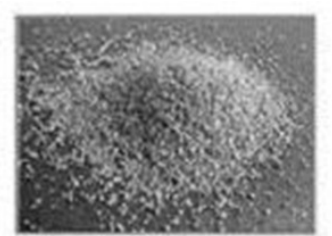

Garnet

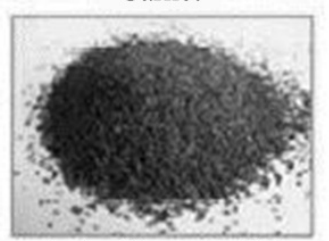

Black Silicon Carbide

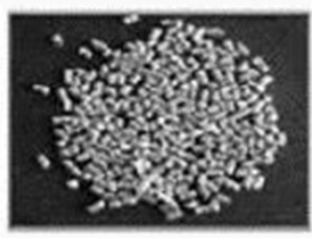

Aliminium Cut Wire

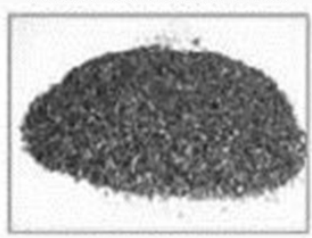

Copper Slag

Figure 3. Different types of common abrasive materials

\subsection{Abrasives Materials}

Abrasive are hard particles used in abrasive water jets to enable cutting much harder materials such as metal, alloys, and composites that cannot be processed using the pure waterjet system. Aluminum oxide, sand, olivine, silicon carbide, and garnet are some of the main abrasive materials used in the industry today [10]. Abrasive particles are hard materials characterized by an outer diameter varying from 50 to $500 \mu \mathrm{m}$, and a mass density of up to $4000 \mathrm{~kg} / \mathrm{m}^{3}$ [13]. Fig. 3 shows the most used types of abrasive particles available in the industry for AWJ applications [14].

The operation of abrasive waterjet cutting is mainly governed by the wearing mechanism of the high-velocity abrasive waterjet on the workpiece. The jet is formed when the abrasive particles are mixed with the high-velocity water in the mixing chamber, which is then forced to pass through a tiny orifice. The accelerated jet exit the nozzle with a very high speed that exceeds twice the speed of sound can easily cut the target object as it passes through the workpiece [15]. When the high-pressure water generated by the pump passes through the nozzle, a high-speed water jet is created, and consequently, a vacuum is produced in the mixing chamber. Due to the pressure difference between the abrasive inlet tube and the mixing chamber, the abrasive particles are sucked into the mixing chamber via a phenomenon called pneumatic transportation mechanism, and the abrasive particles are blended with the water jet. Then the mix passes through the exit nozzle, which produces the high-speed abrasive water jets [16].

\subsection{Mechanism of Abrasive Water Jet Cutting for Ductile Materials}

Erosion is a complex phenomenon that occurs in several aspects of engineering applications namely in gas turbines, rocket nozzles, and abrasive waterjet machining. Cutting of the workpiece by erosion mechanism depends on the flow velocity, size, shape of abrasives particles, angle of attack, and the loading ratio of the abrasive particles [7]. For ductile materials, the impact loads of the abrasive particles falling with very high velocity cause localized plastic strain at the sample piece. The process of material removal occurs when the strain value resulting from the impact loads exceeds the failure capacity of the material. The micro-cutting occurs at a low impact angle, regardless of the global impact angle of the jet with the material being processed [17]. As shown in Fig. 4, the jet traverses over the workpiece at a predefined traverse speed. The kerf is gradually displaced in the traverse direction as the machining continues. In the upper part of the kerf, the abrasive particles are at a shallow inclination angle to the local kerf geometry [16]. 


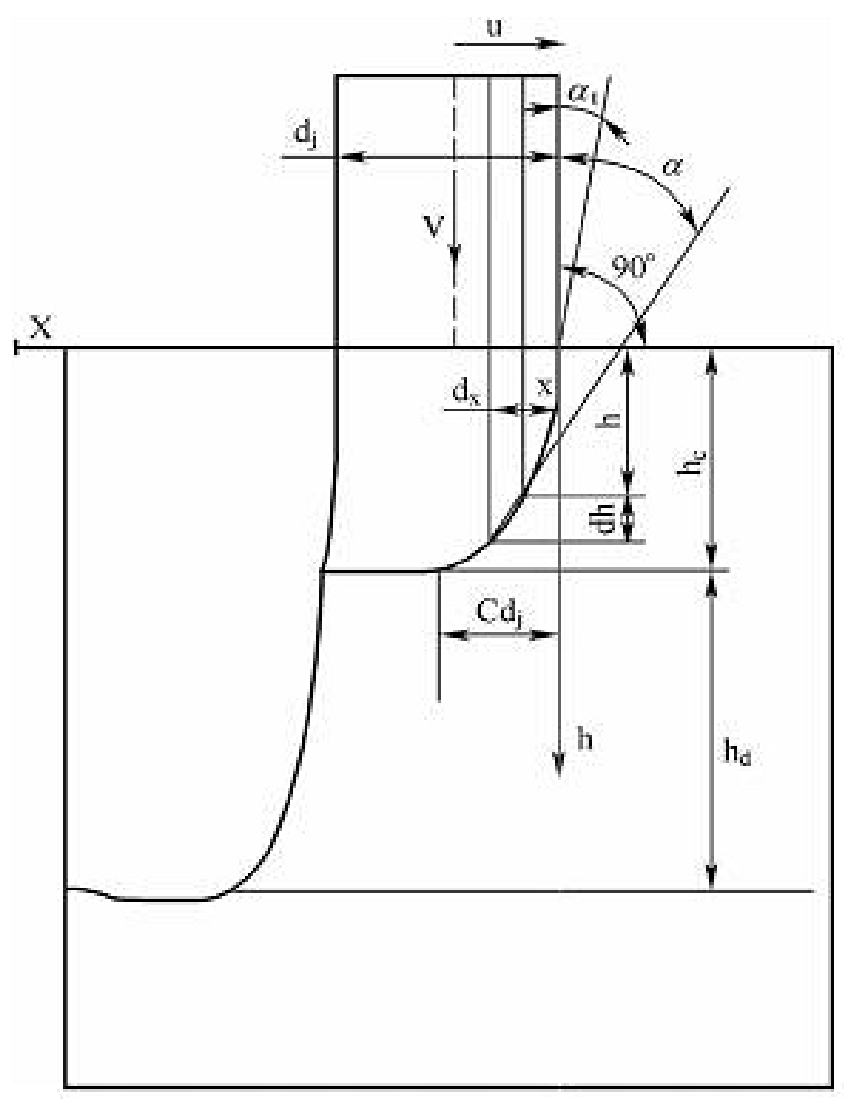

Figure 4. Details of the kerf geometry on a workpiece

Table 1. Summary of Abrasive Water Jet Advantages

\begin{tabular}{|c|c|c|}
\hline No. & Component & Description \\
\hline 1 & $\begin{array}{l}\text { The workpiece is deformed } \\
\text { during the cutting process }\end{array}$ & $\begin{array}{l}\text { Deformation of the workpiece is not taking place during the AWJ cutting process as the sample } \\
\text { is not subjected to heat or mechanical stress. }\end{array}$ \\
\hline 2 & Thermal distortion & $\begin{array}{l}\text { The heat generated is instantaneously carried away by the water. As a result, no temperature } \\
\text { rise occurs in the workpiece [15]. }\end{array}$ \\
\hline 3 & High machining adaptability & $\begin{array}{l}\text { Abrasive waterjet is an effective technique in machining, thus, many hard-to-cut engineering } \\
\text { materials such as steel, concrete, alloys, high strength advanced composites can be easily cut } \\
\text { using this technology. }\end{array}$ \\
\hline 4 & $\begin{array}{l}\text { Easy integration with } \\
\text { mechanical manipulator }\end{array}$ & $\begin{array}{l}\text { AWJ machining can easily be integrated into computer-controlled cutting systems and six } \\
\text { degrees of freedom robots. }\end{array}$ \\
\hline 5 & Availability & $\begin{array}{l}\text { AWJ system depends on the pump, water (operating fluids), silica, and sand which are } \\
\text { classified as low cost and abundant materials, so the AWJ process can be considered as widely } \\
\text { available. }\end{array}$ \\
\hline 6 & Low water consumption & $\begin{array}{l}\text { This technique is not consuming a lot of water, as the average water consumption of an } \\
\text { abrasive water cutting unit is around } 0.5 \text { liter per minute. }\end{array}$ \\
\hline 7 & $\begin{array}{l}\text { Safety and environmental } \\
\text { Degradation issues }\end{array}$ & $\begin{array}{l}\text { As there is no generated heat during the cutting process, the chance of having a fire hazard is } \\
\text { minimal. In addition, there is no danger from flying objects or radiation emission, thus, safety } \\
\text { and environmental issues related to AWJ are negligible. }\end{array}$ \\
\hline 8 & Thin cut & $\begin{array}{l}\text { AWJ is often preferred to other cutting techniques as it can produce thin cuts with precisely } \\
\text { controlled direction and cutting penetration [1]. }\end{array}$ \\
\hline 9 & Good surface quality & $\begin{array}{l}\text { AWJ cutting can produce a high-quality surface finish. For instance, if } 60 \text { to } 100 \text { grit abrasive } \\
\text { material is used at a flow rate of } 0.22 \text { to } 1.1 \mathrm{~kg} / \mathrm{min} \text {, a clean-finished surface with a roughness } \\
\text { of } 3.2 \text { to } 6.3 \mu \mathrm{m} \text { can be achieved. }\end{array}$ \\
\hline
\end{tabular}




\subsection{Advantages of Abrasive Water Jet System}

AWJ cutting technology has many advantages as compared to other nonconventional cutting techniques [18, 19]. The AWJ cutting can offer the following advantages as compared with traditional and nontraditional machining processes as described in Table 1.

\subsection{Classifications of Abrasive Water Jets Nozzles}

The review of the literature shows that there are various types of abrasive jets nozzles. Some of the most common types are discussed in the following paragraphs:

\subsubsection{Single water Jet Nozzle with Side Entry Supply}

Single water jet nozzles in which the abrasive is supplied from the side are the most common types of AWJ nozzles available in the industry. High-pressure water passes through the orifice to the mixing chamber and produces the high-pressure water jet. The role of the mixing chamber is to blend the abrasives with the pressurized water [16].

\subsubsection{Single Jet Nozzle with Tangential Supply}

As reported by Huang, et al. [16], in this type of AWJ, the inlet tubes for the abrasive are arranged to be along the tangential direction of the mixing chamber, and a parallel point for air supply is provided at the abrasive inlet. A slurry pump is used to inject the abrasive into the nozzle. The injection of high-pressure water forces the abrasive particles and air entering the mixing chamber at the same time, rotate, move onward, fully mixing the abrasive and water jets. As a result, the cutting efficiency of AWJ can be improved, and the probability of clogging of the nozzle is minimized.

\subsubsection{Multijet Nozzle with Side Entry Supply}

Multiple nozzle jets are arranged in parallel on the top of the nozzle. The nozzles can be distributed into parallel setup and converging multiple jets with side entry supply [16]. This type of multijet nozzle has many advantages, however, due to the limitation of hole spacing, the size of the abrasive jet diameter is large, the mixing effect is good, and the cutting ability is improved, but the width of the grooving is wide. Hence, to reduce the diameter of jets, the axis arrangement of various nozzles can be changed from parallel to convergent along the center of the nozzle.

\subsubsection{Multijet Central Entry Nozzle}

In this type of AWJ, the abrasives enter the mixing chamber from the middle and are mixed with water jets to improve the mixing efficiency. As the mixing effect is not apparent and the radial dimension is large; this type of nozzle is rarely used for industrial applications [16].

\section{Theoretical Analysis of the Particle Acceleration in AWJ}

The mechanism of material removal in AWJ cutting is due to the erosion caused by the impact loads of high-velocity abrasives on the workpiece. A large amount of kinetic energy is transferred to the work material by the abrasives particles that strike the workpiece at an approximated rate of one million collisions per second. The damages caused to the workpiece by the impact of solid particles mixed with the accelerating fluid are called erosion. The parameters affecting the material removal rates and the depth of cut include the water pressure, the diameter of the orifice, length and diameter of mixing tube and, type and size of abrasive materials, abrasive flow rate, traverse speed, cutting angle and the type and hardness of the material [7]. Fig. 5 shows a schematic diagram of abrasive water jet cutting parameters [20]. 


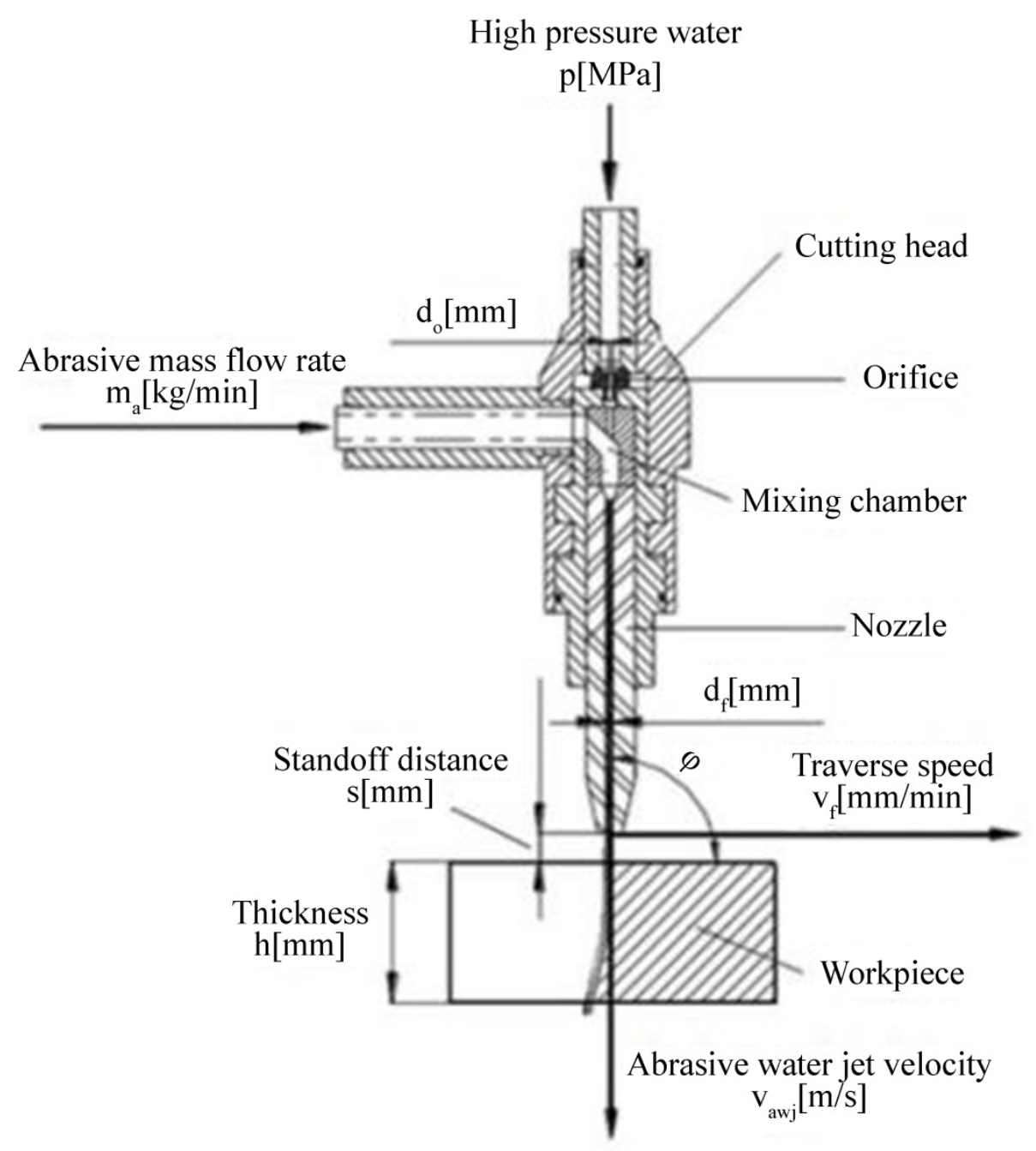

Figure 5. Schematic diagram of abrasive water jet cutting machine

\subsection{Theory of AWJ Cutting for Ductile Material}

The amount of material that can be removed by a single abrasive particle is a function of the particle's mass, $m a$, and velocity, $v a$. The particle's kinetic energy, EP, kcan be calculated using the following equation [21]:

$$
E P_{k}=\frac{1}{2} m_{a} v_{a}^{2}
$$

Similarly, the kinetic power, PP, kin, of the cutting jet can be written as a function of the particle's mass flow rate $\dot{m} a$, and its velocity as follows:

$$
P P_{k}=\frac{1}{2} \dot{m}_{a} v_{a}^{2}
$$

This means, to maximize the abrasive kinetic power of the cutting jet the velocity of the abrasive particles, and the abrasive mass flow rates must be increased. The physics associated with the velocity of abrasive particles exiting the nozzle is a complex phenomenon of all abrasive waterjet process parameters and the geometrical design of the waterjet nozzle. It is a function of the momentum transfer efficiency, $\Psi$ a, between the waterjet and the abrasives [21].

$$
\nu_{a}=\psi_{a} \nu_{w}
$$

The abrasive mass flow rate is an input parameter, but in practice, it is generally chosen to be proportional to the waterjet mass flow rates by a proportionality constant, $R$ as depicted in Equation 4.

$$
\dot{m}_{a}=R \dot{m}_{w}
$$

The kinematic power of the abrasive cutting jet can be presented as follows [21]:

$$
P_{a, k}=\frac{1}{2} R \dot{m}_{w} \psi_{a}^{2} v_{w}^{2}
$$


The potential energy of the pressure is converted into waterjet kinetic energy. This energy accelerates the abrasive particles that cut the material when struck with the workpiece. Typically, the geometry of AWJ is optimized based on the parameters to be used. However, in some situations, the geometry is controlled by the application and thus the parameters are selected to best cut the material [9]. For offshore decommissioning applications, the water jet geometry, the governing parameters, and the overall setup of the machine must be appropriately designed for the intended decommissioning tasks in deep water.

\subsection{Research Challenges Related to AWJ}

Although the review of the literature shows that, parameters affecting AWJ have been investigated by many researchers, wide experimental investigations are required to fully understand the relationship between the important parameters $[4,22]$. In the following sections, the important components of AWJ that need further investigations are discussed.

\subsubsection{Cutting Head}

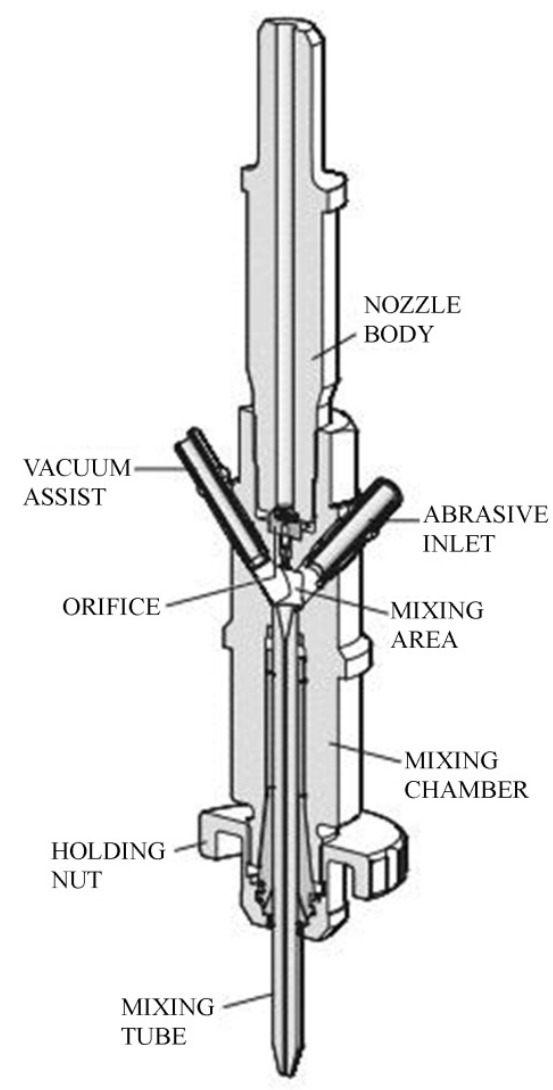

Figure 6. A typical cross-sectional view of a high-performance AWJ cutting head

Selecting the appropriate jewels, geometry and design configurations of the orifice are critical factors in optimizing the performance of a waterjet cutting head. The orifice jewels are commonly made of synthetic sapphire, synthetic ruby, and diamond [23]. The waterjet nozzle creates and aligns the cutting beam of high-pressure water to erode the target object powerfully. The effectiveness of the cutting beam requires delivery of power at the point of cutting efficiently. High-pressure pumps deliver water pressure to the cutting head at pressures varying from 276 to $600 \mathrm{MPa}$. Once the pressurized water is forced to pass through the orifice, a high-velocity waterjet is created. Hashish [24] conducted intensive research to determine the design considerations of the components of an AWJ cutting head and investigated their effects on the quality of abrasive waterjet and concluded that the length of the nozzle should be at least 20 times the diameter of the nozzle to produce good coherent jets. Further, the quality of waterjet flow is critical to ensure optimal and precise cutting [23]. Figure 6 shows a cross-sectional view of an abrasive waterjet cutting head.

\subsubsection{Characteristics of Flow}

Maintaining high-quality stream flow is very much essential to achieve precise cutting in AWJ. The quality of the jet stream is controlled by the alignment and coherency. Alignment is a measure of how true the stream is to the designed direction of travel and it is coaxial to the inside diameter of the mixing tube. Coherency is defined as a measure of the distance traveled by the water stream before the cross-sectional diameter of the stream diameter becomes larger than $200 \%$ of its value when exiting the orifice [23].

\subsubsection{Effect of Orifice Set up on Alignment}

The quality of waterjet stream alignment is influenced by the location of the jewel in the orifice as well as the location of the orifice in the cutting head. This implies that the alignment of registers between the mount and the corresponding surfaces of the cutting head is designed carefully to achieve optimum performance. Any poorly aligned stream will wear down the internal walls of the mixing chamber, and consequently, shorten the design life span of the abrasive waterjet [23].

\subsubsection{Effect of Mixing Tube on Alignment}

The length of the mixing tube can affect the ability of the mixing chamber to focus the streamflow of the jet. If the mixing tube is long, it will provide a longer influence on the abrasive entrained water stream, and consequently result in a better focus as compared to a shorter mixing tube. This will improve the precision of water jets gradually. When analyzing the effect of a smaller inner diameter to larger inner diameter mixing tubes, the following characteristics are affected [23]:

- Gradual increase in the cutting speed

- Decrease in the service life of mixing tubes

- Enhanced precision

- Smaller cutting width 


\subsubsection{Orifice}

The orifice typically consists of a jewel with a hole, placed into a frame. The design of an orifice is governed by several factors such as precision, costs, serviceable life, etc. For a given application, the design life of AWJ is the point at which the cutting quality exceeds the acceptable limits [23]. The service life of the orifice is affected by many parameters such as alignment, fatigue damage of the jewel mount, and erosion. Fig. 7 shows the details of a diamond orifice used for an abrasive water jet [25].

\subsubsection{The Jewel}

Depending upon the application, type, and thickness of material to be cut, and the economics of the cutting process, diamond, ruby, or sapphire are commonly used as a jewel in the AWJ industry. Fig. 8 provides a comparison of jewel leading-edge geometry [23]. The shape of the entry edge of the opening has a great influence over the nature of the flow through the orifice. The diameter of the hole, the opening entrance geometry, and the pressure difference between the entrance and exit influence the quality of the flow. Thus, from the research viewpoint, improving jewel geometry is an important research gap for optimizing AWJ techniques for offshore decommissioning applications.

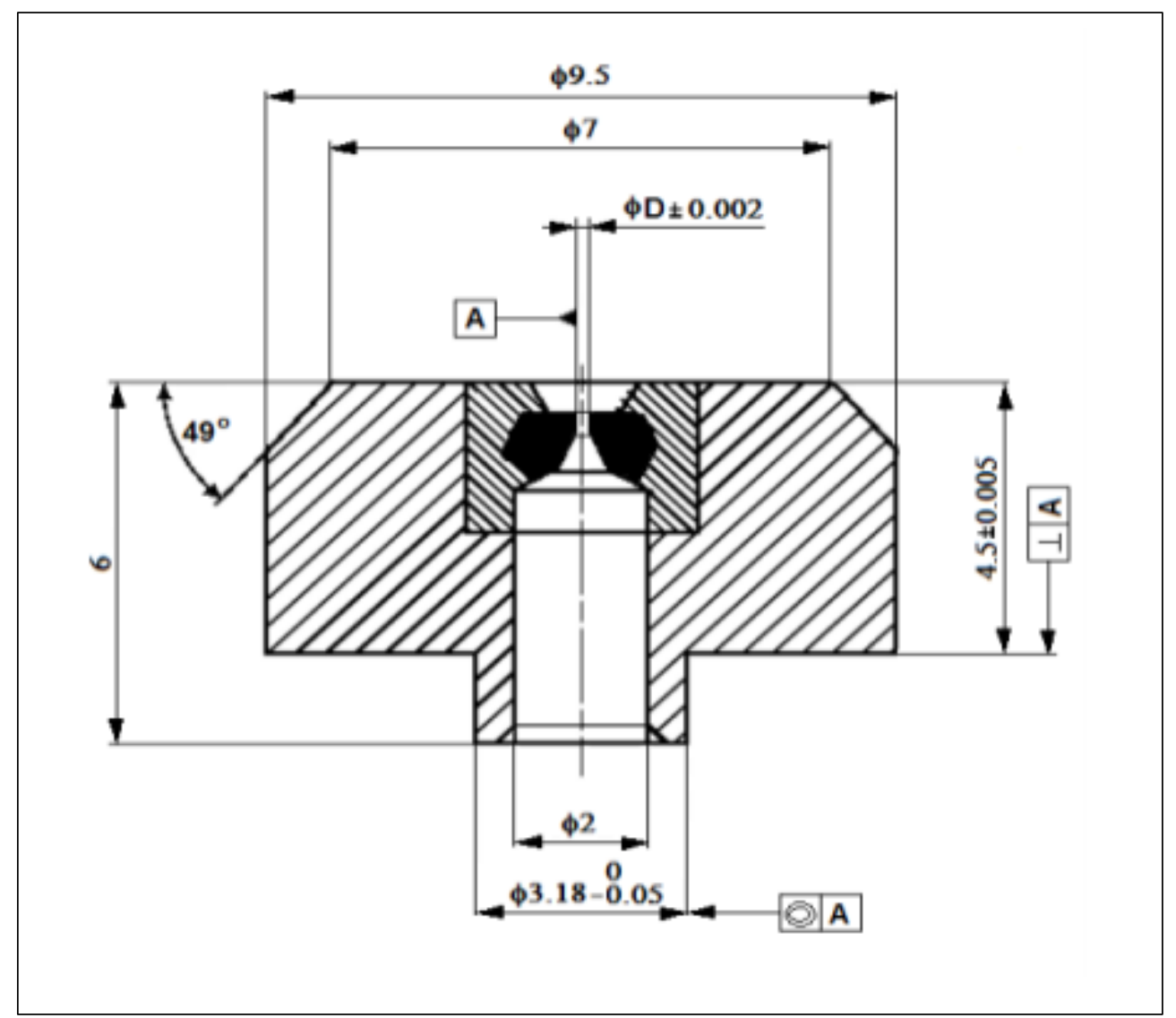

Figure 7. Diamond orifice detail for pressure up to $600 \mathrm{MPa}$

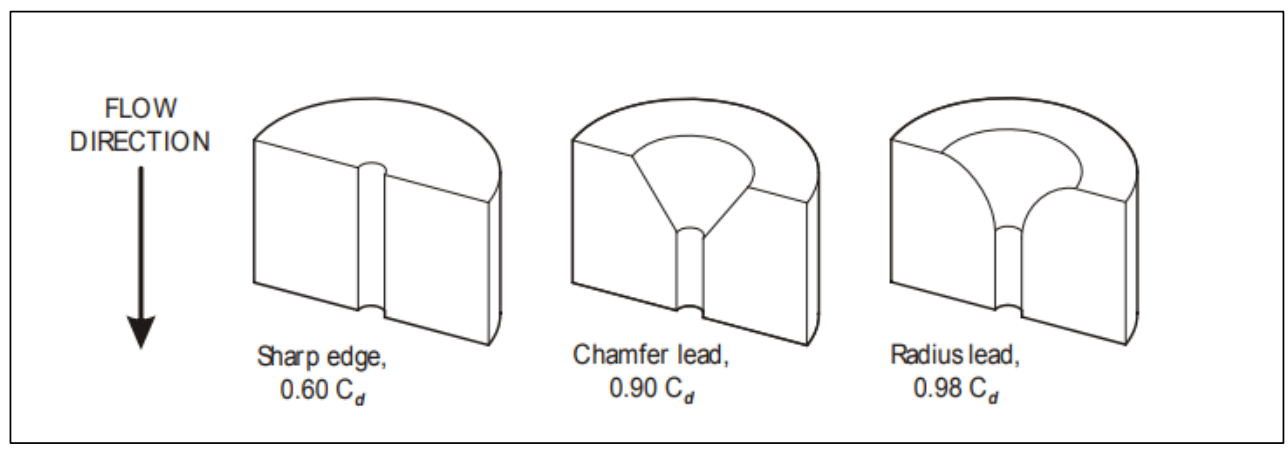

Figure 8. Comparison of jewel leading-edge geometry 
The behavior of the streamflow through an orifice is better explained using the coefficient of discharge, $\mathrm{Cd}$. The value of $\mathrm{Cd}$ increases as the leading edge of the orifice changes from sharp to radius [13]. A larger drag coefficient leads to a greater flow rate. A study by Begenir [26] shows that cone-down mount geometry jewel has the following advantages:

- Produce a greater velocity coefficient and lower discharge coefficient.

- Significantly reduces cavitation and turbulence in the jet.

- Reducing the cone angle will not affect the constricted waterjet.

- The increasing nozzle aspect ratio will not affect the constricted waterjet.

\subsection{Research Gap Related to AWJ}

In the flowing sections, the research gap identified from the literature review is briefly discussed.

\subsubsection{The Nozzles}

The nozzle is the most critical part of the abrasive air-jet equipment. The process can be easily controlled by varying the parameters such as velocity, flow rate, pressure, standoff distance, grit size, and nozzle angle. Response variables like surface finish, material removal rate, kerfs width is producing a cylindrical hole [4]. The characteristics of the cut depend on the velocity, angle of attack, size and shape, and loading ratio of the abrasive particles [7]. Abrasive waterjet machining models must incorporate hydraulic, abrasive, mixing plus cutting settings and cut quality requirements; each category has requirements that must be identified [6].

\subsubsection{Wearing of the Nozzle}

The quick wearing of the nozzle is one of the technical challenges that need to be addressed by researchers. The first abrasive jet nozzles wore down so quickly that the jet would change its characteristics during the production of a single large part. Early abrasive jets were used for simple machining work only. The development of new materials has increased tube life from three or four hours to 50-100 hours. Nozzles have either rectangular or circular shapes and can be straight to the target at an angle of $180^{\circ}$, or a right angle of $90^{\circ}$. As the wear down of an abrasive nozzle increase during the process, the divergence of the jet stream increases resulting in a high degree of inaccuracy $[4,14]$. For decom application, the quick wearing of the nozzle is a challenging technical problem that needs to be addressed by researchers to achieve a cost-effective cutting system for offshore application.

\subsubsection{Design of Orifice}

This is an important issue in AWJ as highlighted by [26]. Thus, this study can be extended to multi-nozzle orifice mounts, where the interaction of multi-abrasive inlets, with a different configuration of nozzle length and orifice geometry, can be considered as an important research gap for MA-AWJ for decom applications.

\subsubsection{Numerical Simulation of AWJ}

As the physics controlling the flow characteristics of AWJ is complex, and the parameters that affect the performance of the AWJ system are complex, designers tend to use numerical simulations tools to improve the complex unsteady turbulent two-phase 3D flow inside an AWJ orifice. In this project, due to the limitation of testing facilities, and to reduce the cost implications of model testing, more emphasis is given to the numerical simulation of AWJ. The application of numerical tools to study the complex physical phenomenon in AWJ is not new. Mostofa, et al. [27] investigated the effect of fixing tube length and reported that the length of the focusing tube is responsible for accelerating the abrasive particles. The study also suggests that the erosion rate increases on the focusing tube wall when the particle shape factor is changed. Generally, if the mass flow rate of the abrasive is very high, the efficiency of the jet will be decreased. When the high-speed turbulent waterjet comes in contact with the air stream, a vortex is developed inside the mixing chamber this vortex has effects on the mixing of different phases. The streamline vectors of the abrasive particles are controlled by the shape of the mixing chamber. At present, the mixing chamber used is generally having a cylindrical shape. However, further investigation can be conducted to visualize the mixing behavior for circular, elliptical, and hyperbolic shaped mixing tubes, as these new shapes might be able to guide the streamline to the jet more effectively. Machine learning is an important tool that is getting much attention as it provides an estimate of the analysis before going into the practical experimentation [28-31]. Various researchers utilized machine learning techniques in AWJ as well [32-36]. In this manner, Wenjun, et al. [37] used the Arbitrary Lagrange-Euler algorithm to create the AWJ model. With the help of the modeling, a relationship was identified between the cutting depth and processing parameters of AWJ. Similarly, Feng, et al. [38] used the Finite Element Method for AWJ cutting, where the model was validated by making a comparison between experimental and theoretical data, while Shahverdi, et al. [39] adopted Arbitrary Lagrangian-Eulerian and Smoothed Particle Hydrodynamics methods for AWJ cutting.

\subsection{Optimization of Parameters}

Since abrasive water jet cutting is comparatively a new process, a review of the existing literature indicates that many improvements and developments are ongoing to optimize and standardize this technique [40]. The cutting rate is determined by several parameters such as waterjet pressure, water flow rate, abrasive mass flow, stand-off 
distance, and material hardness [3]. Chaudhari and Patel [41] conducted an experimental study to optimize the process parameters in AWJ machining. Stainless steel 308 was used in this study and concluded that increasing the water pressure will increase the depth of the cut. In addition, they also observed that increasing the traverse speed led to an increase in surface roughness. In another study Kumar and Shukla [7] determine the effect of particle impact angle on erosion rate. The simulation results for $T i$ alloy show a peak erosion rate at an angle of $45^{\circ}$, which is the typical behavior of a ductile material. They also concluded that the angle at which the maximum erosion occurs is a function of the material. Fig. 9 shows the relationship between the independent variable and the dependant in AWJ [14].

\subsubsection{The Significance of AWJ Parameters}

The effects of AWJ parameters on machining results are presented in Table 2. The table indicates that the important parameters affecting the machining performance of AWJ are volume removal rate, depth of cut, the width of cut, surface waviness surface roughness, and running cost. The importance of AWJ parameters on the machining results are classified as follows:

- Most significant [3]

- $\quad$ Significant [2]

- $\quad$ Less significant [1]

- $\quad$ Not significant [0]

Volume removal rate, depth of cut, and width of cut are the important machining results are the import machining results that are related to decommissioning of jacket platforms. From Table 2, we can conclude that the most important AWJ parameters that influence the machining performance are the pressure $(P)$, water jet orifice diameter (D0), abrasive flow rate (Ma), focusing tube diameter (Dn).

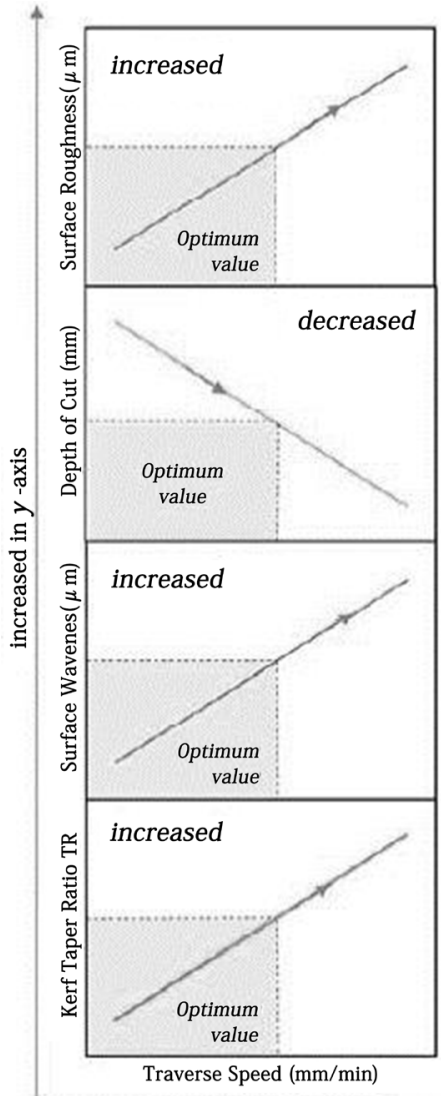

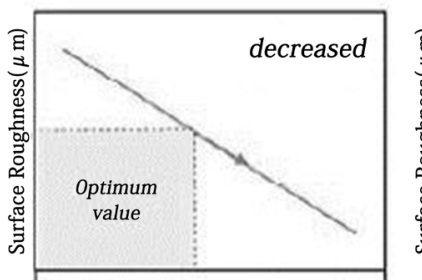
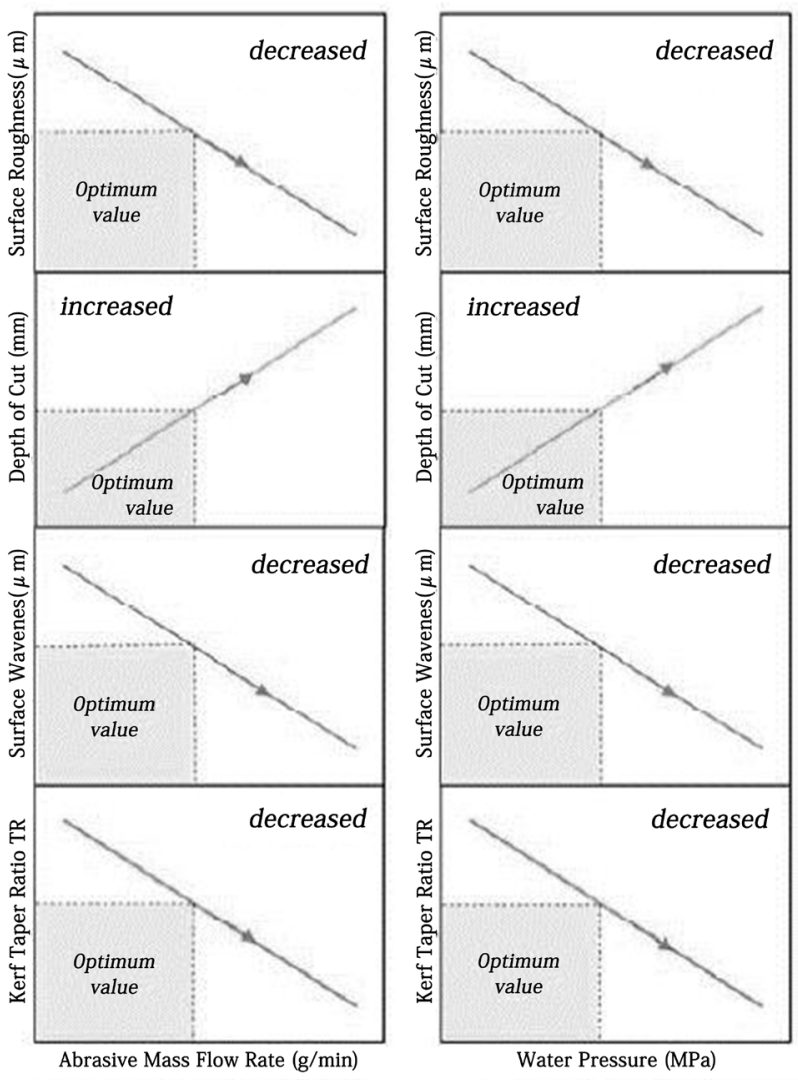

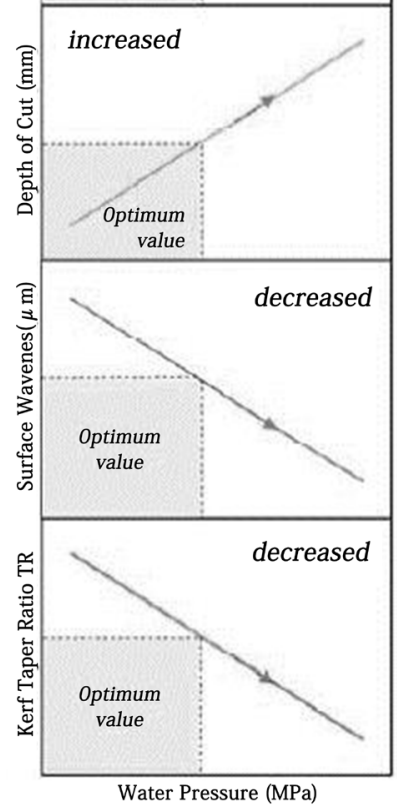

Water Pressure (MPa)

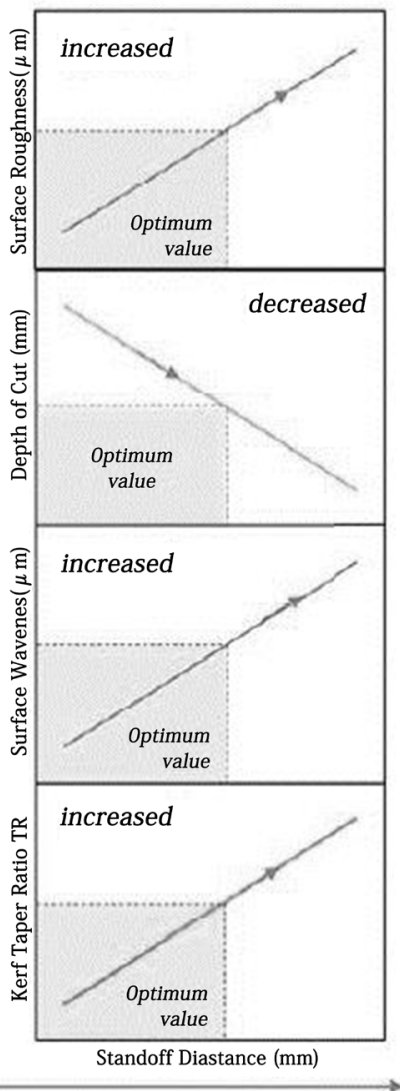

increased in $x$-axis

Figure 9. Relationship between the input data and the output data in AWJ 
Table 2. Significance of AWJ parameters on machining results $[3,42,43]$

\begin{tabular}{|c|c|c|c|c|c|c|c|c|c|c|}
\hline \multirow[b]{2}{*}{ NO. } & \multirow[b]{2}{*}{ Machining Results } & \multicolumn{7}{|c|}{ AWJ Parameters } & \multicolumn{2}{|c|}{ Machining Parameter } \\
\hline & & $\mathrm{P}$ & Do & Ln & Dn & Ma & $\mathrm{D}_{\mathrm{P}}$ & TMa & $\begin{array}{c}\text { Alpha } \\
\text { (degree) }\end{array}$ & $\begin{array}{c}\mathrm{S}_{\mathrm{D}} \\
\text { (Stand Off Distance) }\end{array}$ \\
\hline 1 & Volume Removal Rate & 3 & 3 & 1 & 2 & 3 & 2 & 2 & $\begin{array}{c}90 \\
20-30[16] \\
\end{array}$ & $\begin{array}{c}2 \mathrm{~mm}[3],[15], 4 \mathrm{~mm}[43] \\
2-4 \mathrm{~mm}[44]\end{array}$ \\
\hline 2 & Depth of Cut & 3 & 3 & 0 & 2 & 3 & 2 & 2 & $\begin{array}{c}90 \\
20-30[16] \\
\end{array}$ & $\begin{array}{c}2 \mathrm{~mm}[15],[3], \\
4 \mathrm{~mm}[43]\end{array}$ \\
\hline 3 & Width of Cut & 1 & 0 & 0 & 3 & 1 & 0 & 0 & $\begin{array}{c}90 \\
20-30[16] \\
\end{array}$ & $\begin{array}{c}2 \mathrm{~mm}[3],[15] \\
4 \mathrm{~mm}[43]\end{array}$ \\
\hline 4 & Surface Waviness & 2 & 2 & 1 & 1 & 2 & 1 & 1 & $\begin{array}{c}90 \\
20-30[16]\end{array}$ & $2 \mathrm{~mm}[3],[15], 4 \mathrm{~mm}[43]$ \\
\hline 5 & Surface Roughness & 2 & 2 & 0 & 0 & 1 & 3 & 3 & $\begin{array}{c}90 \\
20-30[16]\end{array}$ & $2 \mathrm{~mm}$ \\
\hline 6 & Running Cost Of Cutting & 1 & 1 & 1 & 1 & 2 & 0 & 0 & $\begin{array}{c}90 \\
20-30[16] \\
\end{array}$ & $2 \mathrm{~mm}[3],[15], 4 \mathrm{~mm}[43]$ \\
\hline
\end{tabular}

Definition of parameters

\begin{tabular}{|c|c|c|c|c|c|c|c|c|}
\hline $\mathrm{P}$ & Do & Ln & Dn & $\mathrm{Ma}$ & $\mathrm{Dp}$ & TMa & Alpha & SD \\
\hline Pressure & $\begin{array}{c}\text { Water Jet Orifice } \\
\text { Diameter }\end{array}$ & $\begin{array}{l}\text { Focusing Tube } \\
\text { Length }\end{array}$ & $\begin{array}{l}\text { Focusing Tube } \\
\text { Diameter }\end{array}$ & Abrasive Flow Rate & Particle Diameter & Material & Angle Of Attack & Standoff Distance \\
\hline
\end{tabular}

Color Coding

\begin{tabular}{|l|l|}
\hline 3 & Most significant \\
\hline 2 & Significant \\
\hline 1 & Less significant \\
\hline 0 & Not significant \\
\hline
\end{tabular}


Table 3. Effect of increasing the value parameter on the depth of cut [14, 15, 41, 45]

\begin{tabular}{|c|c|c|c|c|c|c|c|c|c|c|}
\hline \multirow{2}{*}{ Parameter } & $\mathrm{P}$ & Do & Ln & Dn & Ma & Dp & TMa & Alpha & Stand off & $\begin{array}{c}\text { Traverse } \\
\text { speed }\end{array}$ \\
\cline { 2 - 10 } & Pressure & $\begin{array}{c}\text { water jet } \\
\text { orifice } \\
\text { diameter }\end{array}$ & $\begin{array}{c}\text { focusing } \\
\text { tube } \\
\text { length }\end{array}$ & $\begin{array}{c}\text { focusing } \\
\text { tube } \\
\text { diameter }\end{array}$ & $\begin{array}{c}\text { abrasive } \\
\text { flow rate }\end{array}$ & $\begin{array}{c}\text { particle } \\
\text { diameter }\end{array}$ & material & $\begin{array}{c}\text { Angle } \\
\text { of } \\
\text { attack }\end{array}$ & Distance & \\
\hline $\begin{array}{c}\text { Volume } \\
\text { Removal Rate }\end{array}$ & & & & & & & & & & 1 \\
\hline Depth Of Cut & 1 & & & 0 & 1 & & & 1 & $1[44]$ \\
\hline Width Of Cut & & & & & & & & & & 0 \\
\hline
\end{tabular}

Color Coding

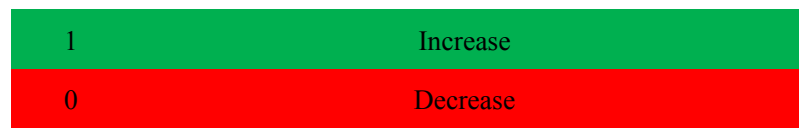

\subsubsection{Effect of AWJ Parameters on the Depth of Cut}

As the abrasive jet system consists of many parameters, this section is highlighting the influence of the most important components in the depth of cut as presented in Table 3. Colour coding was adopted to differentiate the importance of each parameter. The green color means the depth of cut is increasing, while the red color means the depth of cut is decreasing.

\subsection{Multi-Nozzle AWJ for Jacket Leg Cutting}

Based on the literature review, it is obvious that the AWJ cutting system is new, however, to implement this cutting in an offshore application for cutting of jacket legs special consideration is needed to improve the performance of a single nozzle abrasive water jat. Generally, AWJ can be used to cut jacket legs during decommissioning, but this process is costly and time-consuming. Thus, expedite the process of cutting, and reduce the cost, two concepts design for Multi Nozzle abrasive water jets are proposed as follows:

\subsection{MN-AWJ: 3 Lines with 3 Single AWJ}

This proposal consists of a Multi Nozzle abrasive water jet that consists of three individual abrasive water jets connected using separate input lines. This proposal seems reasonable, as the design of the MN-AWJ will be using the optimum design of the single abrasive nozzle, but these individual AWJ will be fixed in a new configuration to act as a single multi-nozzle system. The proposed configuration is shown in Figure 10. As currently, no clear studies are supporting the performance of the proposed MN-AWJ, CFD simulations are being conducted to determine to terminate the performance and operation criteria of the new MN-AWJ.

\subsubsection{MN-AWJ: Two (2) Mainlines with Three (3) Single AWJ}

In this second proposal, the Multi-Nozzle abrasive water jet will consist of two main lines as shown in Figure 11. One line will supply the pressurized water, while the second line will supply the abrasive materials. Then, each of these two mainlines will be subdivided into three individual inlet points to form the Multi-Nozzle Abrasive Water Jet. The challenging part in this new design is how to maintain the required pressure inside the loop and achieve the optimum mixing ratio that will increase the performance of cutting and reduce the overall cost of decommissioning of jacket platforms. Computational Fluid Dynamic simulation is currently ongoing to better understand this new concept design. Then the model test will be conducted for validation purposes. 


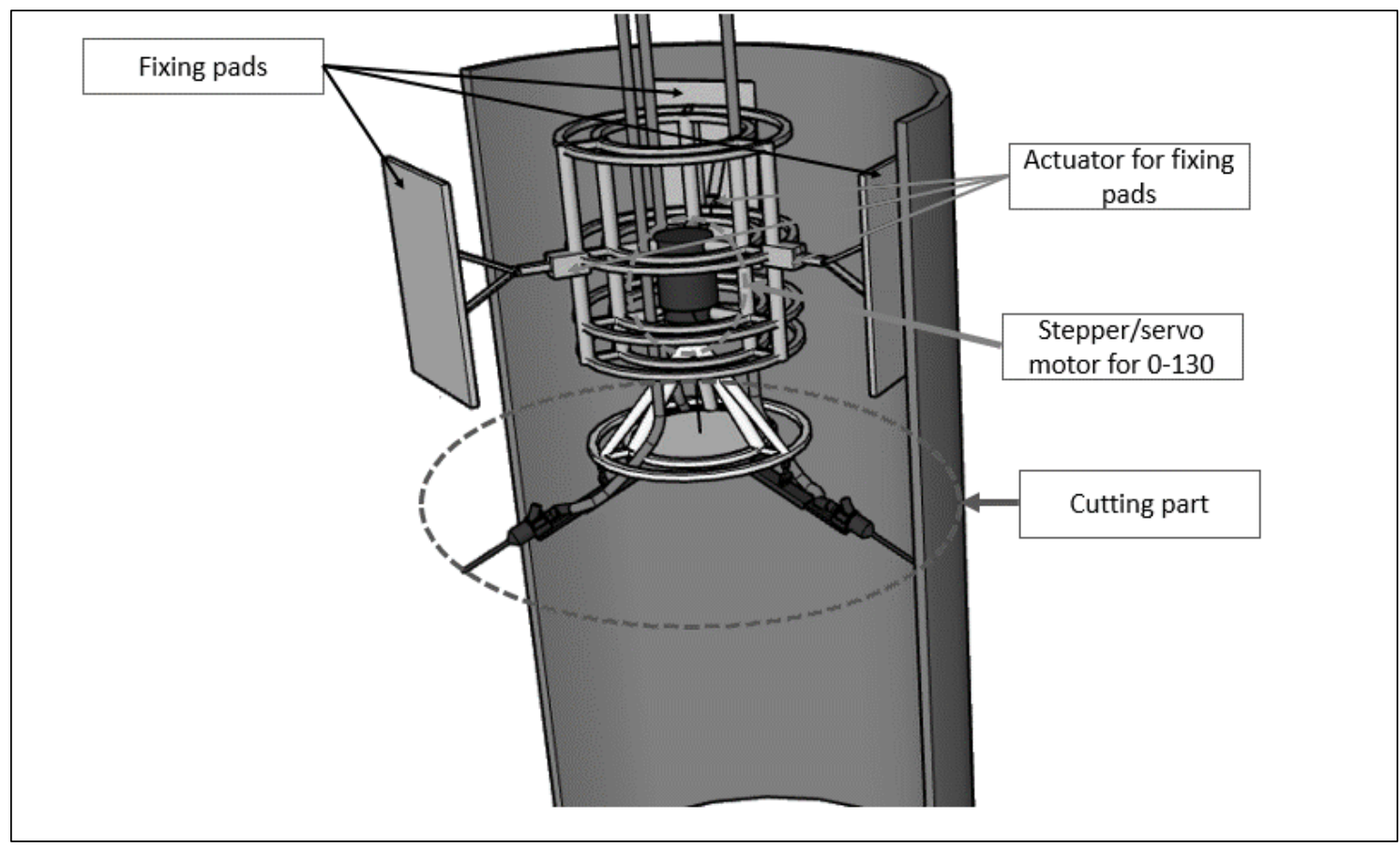

Figure 10. MN-AWJ, 3 lines with 3 nozzles, fixed at 120 degrees, connected in circular arrange

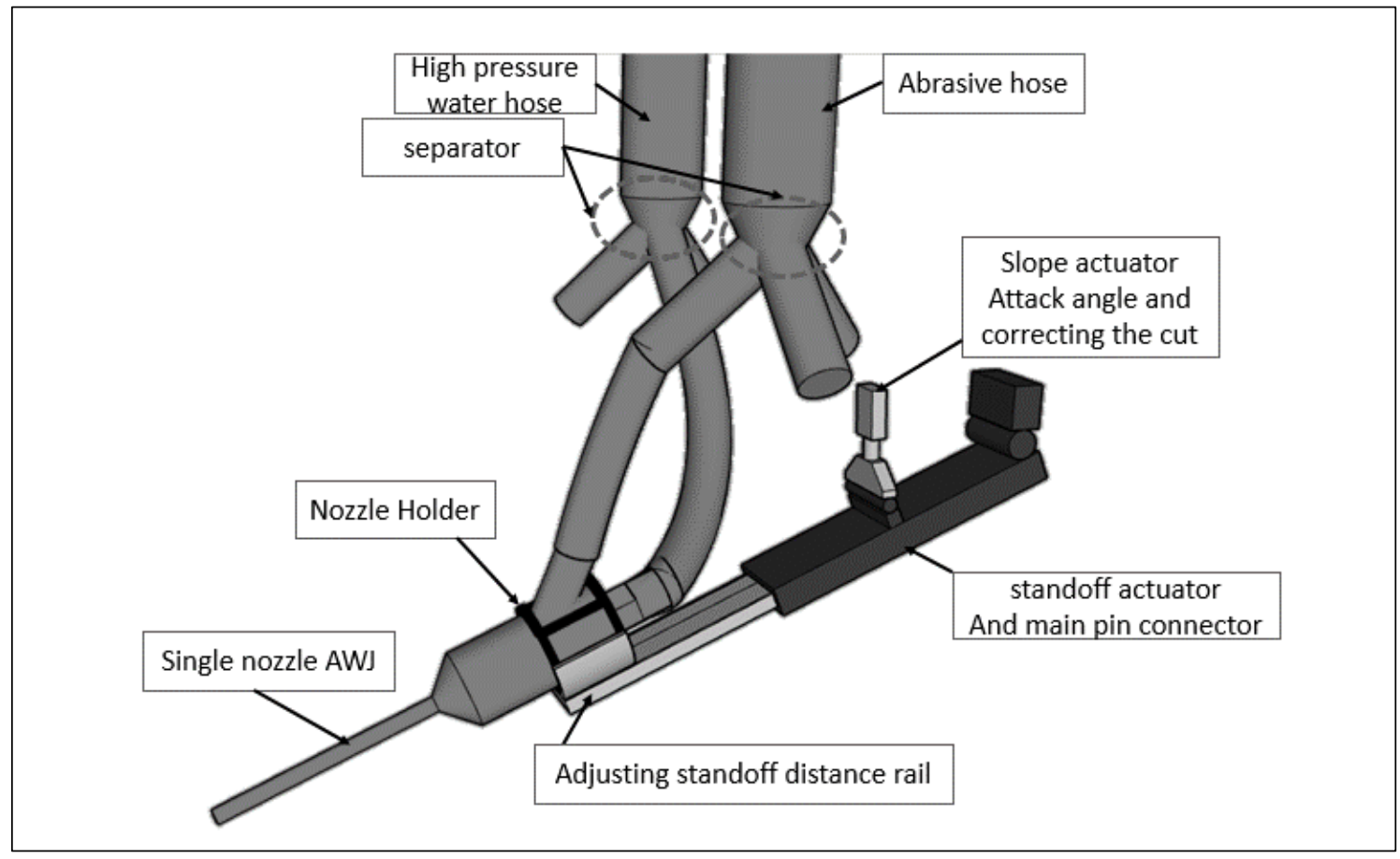

Figure 11. MN-AWJ, two (2) main supply lines that will be divided into three (3) inlet points at the bottom

\section{Conclusions}

- This paper provided a brief background of Abrasive Water Jet (AWJ), components of the abrasive water jet, type of abrasives available in the industry, how abrasive water jet operates. The classification of abrasive water jets nozzles was also discussed. This paper also provided a brief literature review and highlighted the important parameters affecting AWJ. More emphasis was given to Research Question, Theoretical Analysis of the Particle Acceleration in AWJ, Research Challenges, Important parameters affecting AWJ, and the way forward to develop a Multi-Nozzle Abrasive Water Jet based on the Literature Review and the industry need. 
- It is important to determine the optimum feeding angle that can lead to improving the performance of the system and avoid blockage and reduce the probability of clogging and improve performance.

- Single Jet Nozzle with tangential feed is one option that can be investigated. In this type of AWJ, the inlet tubes for the abrasive are arranged to be along the tangential direction of the mixing chamber, and a parallel point for air supply is provided at the abrasive inlet. A slurry pump is used to inject the abrasive into the nozzle. The injection of high-pressure water forces the abrasive particles and air entering the mixing chamber at the same time, rotate, move onward, fully mixing the abrasive and water jets. As a result, the cutting efficiency of AWJ can be improved, and the probability of clogging of the nozzle is minimized.

- Further, increasing the mixing tube size, to avoid clogging, the best angle of the abrasive inlet, the geometry of the chamber are some of the parameters that need in-depth investigation. The design of a mixing chamber which can create a steady suction of the abrasive particles is an important area of research that can be considered in this study. The important geometrical factors affecting the design of AWJ are the mixing chamber which is one of the three main parts of a conventional AWJ nozzle; the other parts are the orifice and the nozzle body.

- As the cutting process of jacket legs during decommissioning is costly and time-consuming, two concept designs for Multi Nozzle AWJ are proposed for Jacket leg cutting. The two concepts are namely a) MN-AWJ: 3 lines with 3 single AWJ and b) MN-AWJ: Two (2) Mainlines with three (3) single AWJ. These concepts designs need to be optimized using CFD simulation \& model testing.

\section{Acknowledgments}

The authors would like to appreciate the YUTP-FRG project: Development Of A Multi-Nozzle Abrasive Water Jet Cutting Tool To Reduce Cutting Time On Large Platforms With Skirt Piles (cost center \#015LC0-088) awarded to Wesam Alaloul for the support.

\section{REFERENCES}

[1] Y. Reinhardt, "Validation of multiphase flow simulations in view of abrasive water jet cutting," ETH Zurich, 2014.

[2] N. A. Zawawi, M. Liew, W. S. Alaloul, L. E. Shawn, M. Imran, and I. Toloue, "Non-Destructive Testing Techniques for Offshore Underwater Decommissioning Projects through Cutting Detection: A State of Review," in SPE Symposium:
Decommissioning and Abandonment, 2019: OnePetro.

[3] L. Ohlsson, "The theory and practice of abrasive water jet cutting," Luleå tekniska universitet, 1995.

[4] S. R. Prasad, D. Ravindranath, and D. Devakumar, "A Research Review on Advanced Approaches in Abrasive Jet Machining," IOSR Journal of Mechanical and Civil Engineering, vol. 16, no. 053, pp. 57-62, 2016.

[5] E. Siores, W. Wong, L. Chen, and J. Wager, "Enhancing abrasive waterjet cutting of ceramics by head oscillation techniques," CIRP annals, vol. 45, no. 1, pp. 327-330, 1996.

[6] M. EITobgy, E. Ng, and M. Elbestawi, "Modelling of abrasive waterjet machining: a new approach," CIRP annals, vol. 54, no. 1, pp. 285-288, 2005.

[7] N. Kumar and M. Shukla, "Finite element analysis of multi-particle impact on erosion in abrasive water jet machining of titanium alloy," Journal of Computational and Applied Mathematics, vol. 236, no. 18, pp. 4600-4610, 2012.

[8] J. Bitter, "A study of erosion phenomena part I," wear, vol. 6, no. 1, pp. 5-21, 1963.

[9] M. Hashish, "Special AWJ nozzles," in American WJTA Conference and Expo, Houston, Texas. WaterJet Technology Association, 2009.

[10] D. Andersson and M. Ingvarsson, "Design of Experiment and Evaluation of Abrasive Waterjet Cutting in Titanium Alloy Sheet," 2015.

[11]A. Perec, "Abrasive suspension water jet cutting optimization using orthogonal array design," Procedia Engineering, vol. 149, pp. 366-373, 2016.

[12]B. Liu, "The rotated injection abrasive jet rust cleaning system," in Proc. 10th Int. Symp. Jet Cutting Technology. Elsevier Sci. Publ. Ltd., London-New York, 1991, pp. 221-233.

[13] M. Hashish, "Abrasive-waterjet (AWJ) studies," Water Jetting, pp. 13-48, 2002.

[14]M. S. Alsoufi, "State-of-the-Art in Abrasive Water Jet Cutting Technology and the Promise for Micro-and Nano-Machining," International Journal of Mechanical Engineering and Applications, vol. 5, no. 1, p. 1, 2017.

[15]A. El-Domiaty, M. Shabara, A. Abdel-Rahman, and A. Al-Sabeeh, "On the modelling of abrasive waterjet cutting," The International Journal of Advanced Manufacturing Technology, vol. 12, no. 4, pp. 255-265, 1996.

[16]Z. Huang, G. Li, S. Tian, X. Song, M. Sheng, and S. Shah, Abrasive Water Jet Perforation and Multi-Stage Fracturing. Gulf Professional Publishing, 2017.

[17] S. Paul, A. Hoogstrate, C. Van Luttervelt, and H. Kals, "Analytical and experimental modelling of the abrasive water jet cutting of ductile materials," Journal of Materials Processing Technology, vol. 73, no. 1-3, pp. 189-199, 1998.

[18]C. P. Selvan, "Abrasive waterjet cutting surfaces of ceramics-an experimental investigation," International Journal of Advanced Scientific Engineering and Technological Research, vol. 1, no. 3, 2012.

[19] P. Badgujar and M. Rathi, "Abrasive Water jet Machining-A 
State of Art," IOSR Journal of Mechanical and Civil Engineering (IOSR-JMCE) e-ISSN, pp. 2278-1684, 2014.

[20]R. Selvam, L. Karunamoorthy, and N. Arunkumar, "Investigation on performance of abrasive water jet in machining hybrid composites," Materials and Manufacturing Processes, vol. 32, no. 6, pp. 700-706, 2017.

[21]P. Miles and A. Henning, "PUMPING EFFICIENCY'S EFFECT ON CUTTING PERFORMANCE."

[22] J. Olsen and J. Zeng, "the state-of-the-art of precision abrasive waterjet cutting," in Proceedings of the 8th Pacific Rim International Conference on Water Jet Technolog, 2006.

[23] M. Powell, "Optimization of UHP Waterjet Cutting Head, The Orifice," Flow International, while the date of the publication is unknown, it is believed to be prior to Aug, vol. 19, p. 19, 2009.

[24] M. Hashish, "Inside AWJ nozzles," in Proceedings of 12th WJTA conference, 2003, pp. 17-19.

[25] M. R. Radovanović, "Performances of Abrasive Water Jet Cutting with Hyper Pressure," International Journal of Modeling and Optimization, vol. 7, no. 5, 2017.

[26]A. Begenir, "The role of orifice design in hydroentanglement," 2003.

[27] M. G. Mostofa, K. Y. Kil, and A. J. Hwan, "Computational fluid analysis of abrasive waterjet cutting head," Journal of mechanical science and technology, vol. 24, no. 1, pp. 249-252, 2010.

[28] S. E. Taşabat, T. Özçay, S. Sertbaş, and E. Akca, "Industry 4.0 Application on Diagnosis Prediction of Construction Machinery: A New Model Approach," Civil Engineering and Architecture, vol. 8, no. 4, pp. 404-416, 2020. DOI: 10.13189/cea.2020.080402.

[29] W. S. Alaloul, M. A. Musarat, M. B. A. Rabbani, Q. Iqbal, A. Maqsoom, and W. Farooq, "Construction Sector Contribution to Economic Stability: Malaysian GDP Distribution," Sustainability, vol. 13, no. 9, p. 5012, 2021.

[30]H. Bukhari, W. S. Alaloul, M. A. Musarat, S. Akram, I. Tabassum, and M. Altaf, "Materializing Low-Cost Energy-Efficient Residential Utility through Effective Space Design and Masonry Technique-A Practical Approach," Civil Engineering and Architecture, vol. 9, no. 2, pp. 357-374, 2021. DOI: 10.13189/cea.2021.090209.

[31] M. B. A. Rabbani, M. A. Musarat, W. S. Alaloul, M. S. Rabbani, A. Maqsoom, S. Ayub, H. Bukhari, and M. Altaf, "A Comparison Between Seasonal Autoregressive Integrated Moving Average (SARIMA) and Exponential Smoothing (ES) Based on Time Series Model for Forecasting Road Accidents," Arabian Journal for Science and Engineering, pp. 1-26, 2021.

[32] L. Guo, S. Deng, and X. Yang, "Numerical simulation of abrasive water jet cutting chemical pipeline based on SPH coupled FEM," Chemical Engineering Transactions, vol. 51, pp. 73-78, 2016.

[33]X. Ma, T. Zhu, Y. Fu, Y. Yan, and W. Chen, "Numerical simulation of rock breaking by abrasive water jet," Journal of Coastal Research, vol. 93, no. SI, pp. 274-283, 2019.

[34] B.-s. Nie, J.-q. Meng, and Z.-f. Ji, "Numerical simulation on flow field of pre-mixed abrasive water jet nozzle," in 2008 Asia Simulation Conference-7th International Conference on System Simulation and Scientific Computing, 2008, pp. 247-251: IEEE.

[35] N. Baisheng, W. Hui, L. Lei, Z. Jufeng, Y. Hua, L. Zhen, W. Longkang, and L. Hailong, "Numerical investigation of the flow field inside and outside high-pressure abrasive waterjet nozzle," Procedia Engineering, vol. 26, pp. 48-55, 2011.

[36] D. H. Ahmed, J. Naser, and R. T. Deam, "Particles impact characteristics on cutting surface during the abrasive water jet machining: Numerical study," Journal of materials processing technology, vol. 232, pp. 116-130, 2016.

[37] G. Wenjun, W. Jianming, and G. Na, "Numerical simulation for abrasive water jet machining based on ALE algorithm," The International Journal of Advanced Manufacturing Technology, vol. 53, no. 1, pp. 247-253, 2011.

[38] Y. Feng, W. Jianming, and L. Feihong, "Numerical simulation of single particle acceleration process by SPH coupled FEM for abrasive waterjet cutting," The International Journal of Advanced Manufacturing Technology, vol. 59, no. 1-4, pp. 193-200, 2012.

[39] H. Shahverdi, M. Zohoor, and S. M. Mousavi, "Numerical simulation of abrasive water jet cutting process using the SPH and ALE methods," 2011.

[40] M. Shukla, "Abrasive water jet milling," in Nontraditional Machining Processes: Springer, 2013, pp. 177-203.

[41]H. A. Chaudhari and V. D. Patel, "OPTIMIZATION OF PROCESS PARAMETER IN ABRASIVE WATER JET MACHINING FOR MACHINING," IJARIIE, vol. 4, no. 1, 2018.

[42] S. Anwar, "Modelling of abrasive waterjet milled footprints," University of Nottingham, 2013.

[43]D. S. Reddy, A. S. Kumar, and M. S. Rao, "Parametric optimization of abrasive water jet machining of Inconel $800 \mathrm{H}$ using Taguchi methodology," Universal Journal of Mechanical Engineering, vol. 2, no. 5, pp. 158-162, 2014.

[44]H. A. C. and V. D. P., "OPTIMIZATION OF PROCESS PARAMETER IN ABRASIVE WATER JET MACHINING FOR MACHINING," IJARIIE, vol. IJARIIE-ISSN(O)-2395-4396, 2018.

[45] R. Melentiev and F. Fang, "Recent advances and challenges of abrasive jet machining," CIRP Journal of Manufacturing Science and technology, vol. 22, pp. 1-20, 2018. 